\title{
Transperitoneal Transvesical Laparoscopic Repair of Vesicovaginal Fistulae: Experience of a Tertiary Care Centre in Northern India
}

\author{
Vishwajeet Singh $^{a} \quad$ Rahul J. Sinha $^{a}$ Seema Mehrotra ${ }^{b}$ Dheeraj K. Gupta ${ }^{a}$ Smita Gupta ${ }^{b}$ \\ Department of aUrology and 'Obstetrics \& Gynaecology, King George Medical University, Lucknow, Uttar Pradesh, India
}

\author{
Key Words \\ Transperitoneal approach • Laparoscopic surgery • \\ Vesicovaginal fistulae
}

\begin{abstract}
Objective: To present our experience of treating supratrigonal vesicovaginal fistulae by laparoscopic technique and their long-term follow-up. Material and Methods: Between January 2008 and June 2012, 28 cases of supratrigonal fistulas were repaired by laparoscopic transperitoneal transvesical technique with interposition flap. The obstetric fistula was present in 18 and gynecologic fistula in 10 patients. Single supratrigonal fistula was present in 26 patients and in 2 patients there were 2 fistulae lying side to side. The vaginal opening was closed as single layer interrupted suture and cystotomy closed as single layer continious suture by 3-0 polygalactin. The omentum was used as interposition flap in all except 2 cases in whom postero-superior vesical fold of peritoneum was used. The open conversion was required in 2 cases. The urethral catheter was removed in 4 weeks following a micturating cystogram. Result: The mean fistula size was $1.2 \mathrm{~cm}$ (range $0.8-2.5 \mathrm{~cm}$ ). Open conversion was performed in 2 cases of whom one had excess carbon-dioxide retention and cardiac arrhythmia and in another case the needle of 3-0 polygalactin was avulsed and lost in peritoneal cavity which was recovered following laparotomy. All patients were continent following the catheter removal. The median follow-up is 24 months. None developed any complication related to laparoscopic repair till last follow-up.
\end{abstract}

\section{KARGER}

Fax +4161306 1234

E-Mail karger@karger.ch

www.karger.com
(C) 2013 S. Karger AG, Basel

1015-9770/13/0072-0075\$38.00/0

Accessible online at:

www.karger.com/cur
Conclusion: Laparoscopic repair of supratrigonal vesicovaginal fistulae is an effective and safe minimally invasive treatment with excellent result.

Copyright $\odot 2013$ S. Karger AG, Basel

\section{Introduction}

Vesicovaginal fistula (VVF) is most common acquired urogenital fistula, cause great psychological morbidity to the patients. Majorities of low lying fistulae (trigonal fistulae with or without urethral extension) can be repaired by transvaginal route $[1,2]$. The abdominal route is indicated if fistula is associated with ureterovaginal fistula, high-up fistulas, small capacity bladder requiring augmentation, and multiple failed vaginal attempt of repair with vaginal shortening and stenosis and in cases of multiple VVF [3-5]. Over the past 15 years there have been consistent efforts on the laparoscopic repair of high-up supratrigonal fistulas which can not be repaired transvaginally. Nezhat et al. [6] first reported the laparoscopic repair of VVF in 1994. They further presented the experience of laparoscopic repair of intentional and unintentionally performed cystotomies on 19 patients [7]. Von Theobald et al. [8] reported a laparoscopic repair of VVF with omental $\mathbf{J}$ flap and claimed to be a modification of the technique. Miklos et al. [9] reported the utility of laparoscopic repair even in recurrent fistula. Chibber 
Table 1. Demographic characteristics and operative parameters of patients

\begin{tabular}{lll}
\hline Characteristics & Result/observation & Range \\
\hline Age, years & $24 \pm 7.0$ & $18-45$ \\
Type of fistula & 18 & - \\
$\quad$ Obstetric & 10 & $6-36$ \\
$\quad$ Gynecologic & $14 \pm 7.3$ & - \\
Duration of urinary incontinence, months & supratrigonal & - \\
Location of fistula & & $0.8-2.5$ \\
Number of fistula & 26 & $136-154$ \\
$\quad$ Single & $1.2 \pm 0.39$ & $32-82$ \\
$\quad$ Two & $145 \pm 5.5$ & $17.3-28.6$ \\
Size of fistula, cm & $52 \pm 16.34$ & $140-200$ \\
Patient's height, cm & $22.76 \pm 3.6$ & $50-100$ \\
Body weight, kg & $160 \pm 16.40$ & $4-5$ \\
BMI, kg/m & $70 \pm 14.93$ & $0-2$ \\
Operative time, minutes & $4.5 \pm 0.33$ & $150-250$ \\
Blood loss, ml & $1.5 \pm 0.47$ & $50-100$ \\
Visual pain analog score on day 1 & $200 \pm 29.05$ & $5-7$ \\
Visual pain analog score on day 2 & $70 \pm 15.91$ & $12-24$ \\
Mean dose of Tramadol in mg required in first 24 hours & $6 \pm 0.79$ & $4-54$ \\
Tramadol required in 24-48 hours, mg & $14 \pm 2.15$ & \\
Hospitalization, days & $24 \pm 14.13$ & \\
Time to return of bowel sounds, hours & & \\
Follow-up, months & &
\end{tabular}

et al. [10] reported the experience of laparoscopic repair of both vesicovaginal and vesicouterine fistula with high success rate. Hemal et al. [11] also reported the technique of laparoscopic repair of cervico-vaginal fistula developed following cesarean section. Erdogru et al. [12] in an interesting modification reported the use of fleecebound sealing system for laparoscopic repair of recurrent VVF. Robot assisted laparoscopic fistula repair with excellent result has also been reported [13]. Herein, we present our experience of laparoscopic transperitoneal transvesical repair of supratrigonal vesicovaginal fistula and their long-term follow-up.

\section{Materials and Methods}

Between January 2008 and June 2012, 28 cases of VVF were selected for laparoscopic repair. Ethical clearance was obtained from institutional ethical committee and informed written consent was obtained prior to surgery. Preoperative cystoscopy was performed to record the site, size, number of fistula and their relation to the ureteric orifices. Vaginoscopy was also performed to assess the location of fistula and status of cervix/vaginal vault, vaginal lumen in patients having history of hysterectomy. Our inclusion criteria were based primarily on supratrigonal or very high-up fistulas less than $2.5 \mathrm{~cm}$ with stenosed or incapacious vagina. In all patients complete hemogram, renal function tests, liver function tests, total serum protein and serum albumin and intravenous urogram were performed. The chest X-ray PA view and ECG were performed for assessing the fitness for anesthesia. The patients who had anemia (hemoglobin level $<10 \mathrm{~g} / \mathrm{dl}$ ) were given preoperative blood transfusion and in patients who had hypoprotenemia, they were put on high protein diet for 4-6 weeks. Empirically, in patients who had anemia were given oral antihelminthics to eradicate intestinal worm infestations. In 2 patients the psychiatric consultation for moderate depression was obtained before the operative intervention and treated adequately for 4-6 weeks using antidepressants.

\section{Technical Steps}

The operative steps are described in details in table 1. Step I includes cystoscopy and bilateral ureteric catheterization and insertion of different colored catheter in fistula. Step II includes patient positioning, ports placement and creation of pneumoperitoneum. A $10 \mathrm{~mm}$ infraumbilical open port placement for camera was performed in all cases and carbon dioxide pneumoperitoneum was created with a pressure of $12 \mathrm{mmHg}$. The patient was then put in $30^{\circ}$ to $40^{\circ}$ Trendelenburg position and another $12 \mathrm{~mm}$ port in right iliac fossa and $5 \mathrm{~mm}$ port in left iliac fossa were placed. Step III involves dissection of fistula, closure of vaginal opening, cystotomy closure and interposition of vascularized flaps. This is the most crucial step in fistula closure. The bladder at this stage was inflated with $200-300 \mathrm{ml}$ saline and a deliberate posterior midline cystotomy was performed. The Foley catheter at this stage was clamped to prevent the loss of pneumoperitoneum. Through 
the cystotomy inside of bladder was inspected and fistulous tract identified by presence of different colored ureteric catheter (fig. 1). The cystotomy was extended upto the fistula. A plane between the bladder and vaginal wall was developed by sharp dissection. The fistula was circumferentially dissected to make completely free from bladder wall (fig. 2). In cases having two fistulae lying side to side (fig. 3) the thin bladder wall between two fistulae was cut to make the single fistulous opening. The anterior bladder wall and dome were lifted up and tucked gently against the inner surface of anterior abdominal wall by a silk thread inserted percutaneously mounted on laparoscopic fascial port closure needle. The silk thread was removed at the end of the procedure. The vaginal opening of fistula was closed by 3-0 polygalactin as interrupted single layer. The ureteric catheter lying in fistulous opening was pulled out before tying the final knot. The omentum was tucked at the suture line (fig. 4). The bladder was then closed as single layer continuous suture by 3-0 polygalactin. The bladder was filled by 200 to $300 \mathrm{ml}$ of normal saline under gravity to check any apparent leakage and additional interrupted suture was taken at leakage sites. The omentum was also tucked to the bladder suture line in its most distal part. In 2 cases there was deficient omentum for interposition in which the peritoneal covering from posterosuperior bladder wall was placed as interposition flap and tucked to the vaginal suture line following closure of bladder. Step IV The final finishing step includes insertion of peritoneal closed suction drain and shifting of the patient to specialized postoperative recovery room.

There were 2 laparoconversions. First case was due to avulsion of needle which was lost in peritoneal cavity and recovered by laparotomy and in another case open conversion was done because of excessive carbondioxide retention and cardiac arrythmia.

The visual pain analog score was recorded on first and second postoperative days. Intravenous tramadol on demand was given to the patients. The patients were allowed liquids on first postoperative day following return of bowel sounds and semisolid and solids are allowed from second postoperative day. They were discharged between 5 and 7 days and then called after 4 weeks from the date of operation and a cystogram was performed before catheter removal. All patients were asked to abstain from sexual intercourse for 3 months from the date of operation.

\section{Results}

The mean age of patient was $24 \pm 7.0$ years. The obstetric fistula was present in 18 patients and gynecologic type in 10 patients respectively (table 2). The mean duration of urinary incontinence was $14 \pm 7.3$ months (range 6-36 months) and the mean fistula size was $1.2 \pm 0.39$ $\mathrm{cm}$ (table 2). In 2 patients there were 2 fistulae lying side to side, larger was $1.5 \mathrm{~cm}$ and smaller $10 \mathrm{~mm}$. The laparoscopic repair was completed successfully in 26 cases and open conversion was required in 2 cases. The mean operating time was 160 minutes (range 140-200 minutes) and the mean estimated blood loss was $70 \mathrm{ml}$ (range 50-100 ml). The mean visual pain analog score on first postoperative day was $4.5 \pm 0.33$ (range $4-5$ ) and on

Laparoscopic Repair of Vesicovaginal Fistulae second postoperative day it was $1.5 \pm 0.47$ (range $0-2$ ) (table 2). The mean dose of tramadol on first postoperative day was $200 \pm 29.05 \mathrm{mg}$ and on second postoperative day it was $70 \pm 15.91 \mathrm{mg}$ (table 2). None of patient developed paralytic ileus or any bowel related complication. All patients were continent following catheter removal. The frequency of urine was seen in 5 patients managed by oral anticholinergics for $2-4$ weeks. The mean period for hospitalization was $6 \pm 0.79$ days (range 5-7 days). The median follow-up was $24 \pm 14.13$ months (table 2 ).

\section{Discussion}

Laparoscopic repair of vesicovaginal fistula was reported first by Nezhat et al. [6, 7] in 1994 and they further reported the bladder repair in intentionally and unintentionally performed cystotomies in 19 patients. The laparoscopic VVF repair has distinct technical advantages (table 3) reported in various studies [10, 12, 14-16]. There are many case reports and series on laparoscopic technique of VVF repair [6-19]. These studies have variations in the basic techniques of approaching the fistula either by transvesical or extravesical routes, number of ports used, laparoconversions, differences in operative time, hospital stay, duration of catheterization, complications and overall success rate (table 4 ). There are 2 basic principles of laparoscopic repair. These are transperitoneal nontransvesical approach $[9,14,17,18]$ and transperitoneal transvesical approach respectively [10-12, 15-17]. In present study, laparoscopic transvesical VVF repair was performed in all cases. In the technique of transperitoneal nontransvesical approach, Lee et al. [14] described that posterior longitudinal cystotomy is not given rather they develop a plane between posterior bladder wall and anterior vaginal wall to reach the fistula. The vaginal and vesical fistulous openings are repaired separately without any interposition graft. The main drawback of this study is that it does not provide information about the position of ureteric orifices and surgeons have fear of injuring ureters. Contrary to this, the technique of transperitoneal transvesical VVF repair allows visualization inside the bladder which gives direct information of location of ureteric orifices and hence gives confidence to surgeons $[10,12,16]$.

Most of the vesicovaginal fistulae can be repaired by transvaginal route which is associated with least morbidity $[20,21]$. The abdominal approach is indicated selectively and these are the fistulae suitable for laparoscopic repair [10-21]. In present study our inclusion criteria 


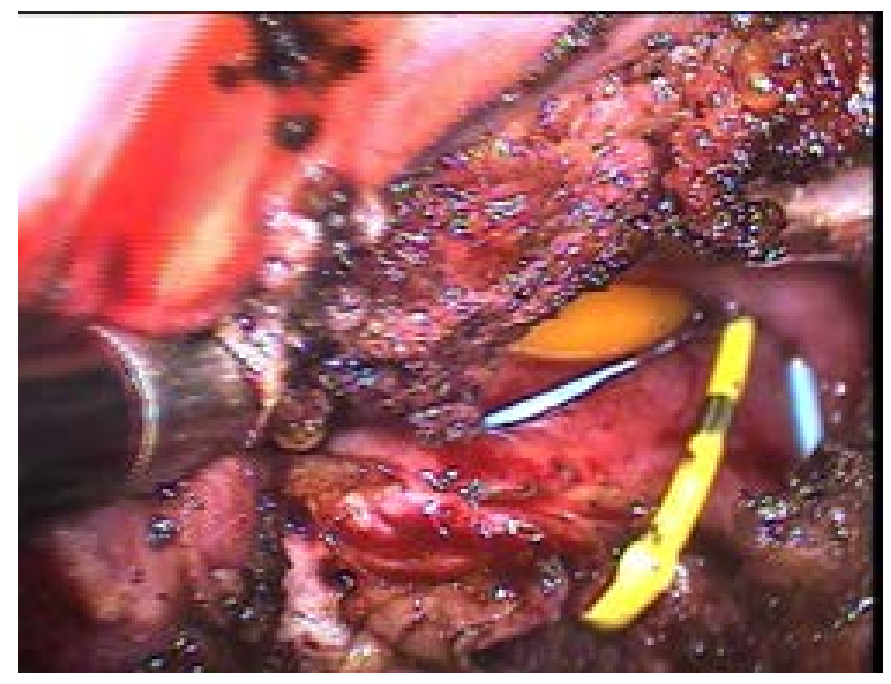

Fig. 1. The ureteric catheters inserted in ureter are shown blue colored and the fistulous opening containing yellow colored ureteric catheter.

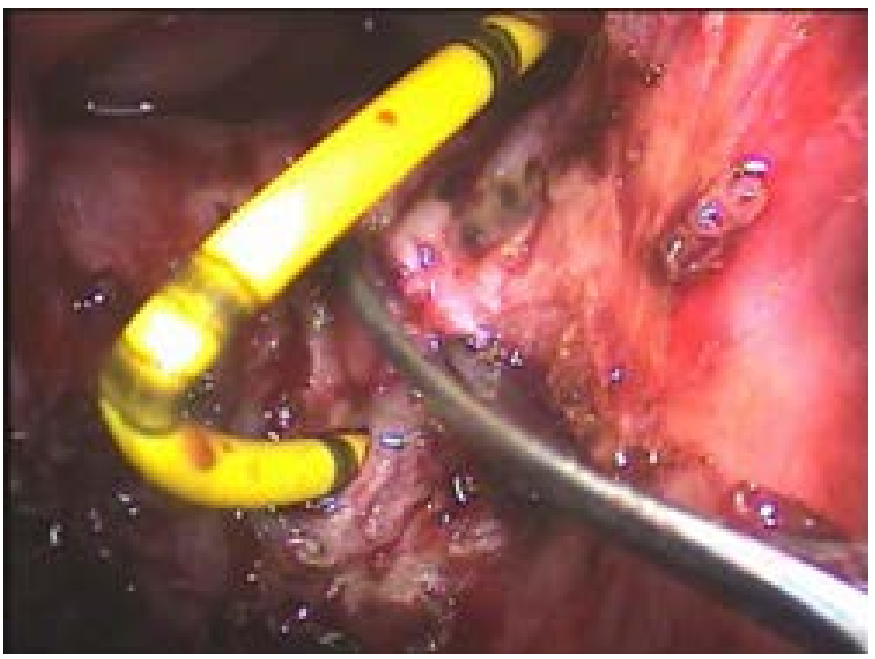

Fig. 2. The fistulous opening was circumferentially dissected and made free from bladder wall.

were based primarily on supratrigonal or very high-up fistulas less than $2.5 \mathrm{~cm}$ with stenosed or incapacious vagina which makes them unsuitable for transvaginal repair. The laparoscopic repair certainly has advantages (table 3) which decrease the morbidity of transabdominal VVF repair and at the same time maintaining the high

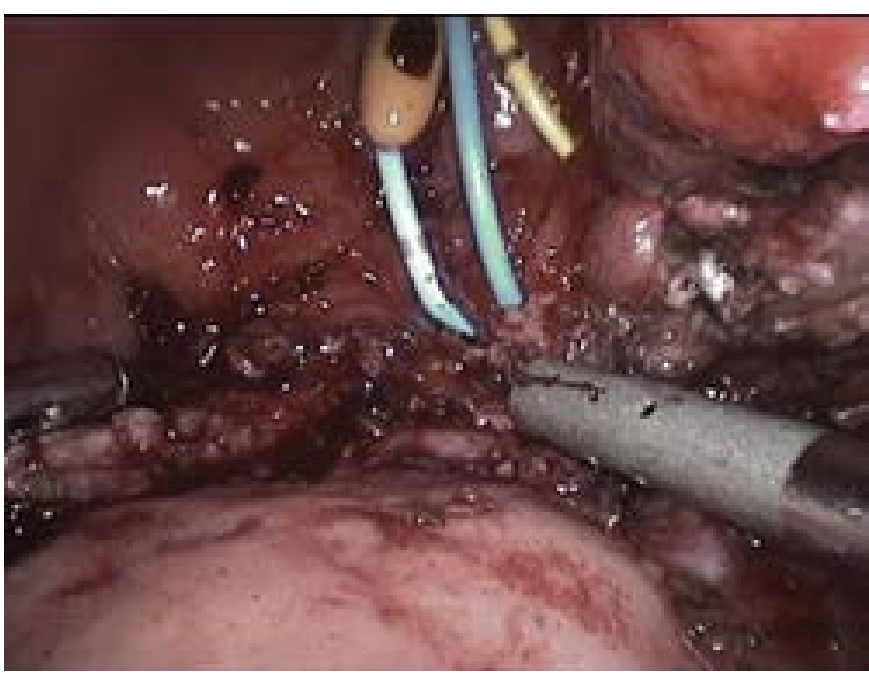

Fig. 3. Two fistulae (denoted by presence of blue colored ureteric catheter) lying side to side with thin bladder wall in between.

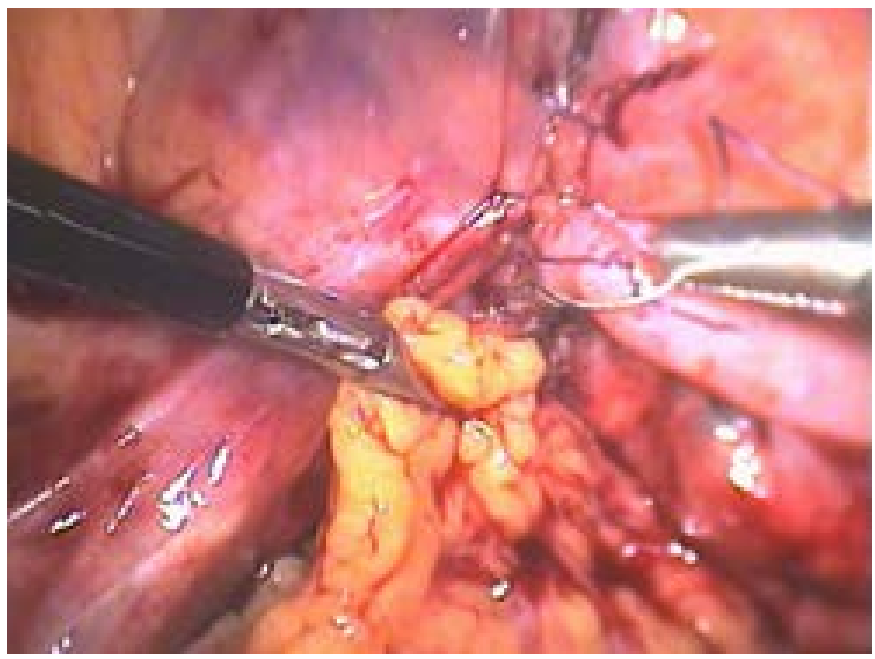

Fig. 4. The omentum insertion in process between bladder and vaginal repairs.

success rate comparable to open repair. To best of our knowledge, our series is the largest series of laparoscopic repair with $100 \%$ success rate of fistula repair. Though the laparoscopic repair has excellent success, the major disadvantage with this technique is the difficult intracorporeal suturing. The robotic assistance has the potential 
Table 2. The technical steps in laparoscopic VVF repair

\begin{tabular}{|c|c|}
\hline Technical steps & Elaboration of the procedure \\
\hline Step I & $\begin{array}{l}\text { 1. Under general anesthesia patient placement in lithotomy position for cystoscopy and bilateral ureteral catheteriza- } \\
\text { tion by } 6 \mathrm{~F} \text { ureteric catheter. A different colored ureteric catheter insertion in fistula to recognize it intraoperatively } \\
\text { 2. Vaginal packing with Vaseline soaked cotton gauze } \\
\text { 3. Foley catheterization and securing the bilateral ureteric catheters }\end{array}$ \\
\hline Step II & $\begin{array}{l}\text { 1. Patient placement in supine position with both arms lying by side of patient } \\
\text { 2. Trendelenburg position of } 30^{\mathrm{O}}-40^{\circ} \\
\text { 3. Infraumbilical open port }(10 \mathrm{~mm}) \text { placement for camera and creation of pneumoperitoneum } \\
\text { 4. Other } 2 \text { ports (one } 12 \mathrm{~mm} \text { and one } 5 \mathrm{~mm}) \text { placement under vision as closed port placement in bilateral iliac fossa }\end{array}$ \\
\hline Step III & $\begin{array}{l}\text { 1. Inspection of the pelvic peritoneal cavity and assessment of the location of fistula } \\
\text { 2. Dissection of the fistula and making planes between bladder and vagina } \\
\text { 3. A midline posterior cystotomy is made to recognized the fistulous opening by presence of different colored ure- } \\
\text { teric catheter and more precise dissection between bladder wall flap and vaginal wall } \\
\text { 4. Lifting and securing anterior bladder wall against inner anterior abdominal wall by silk thread mounted on lap- } \\
\text { aroscopic fascial port closure needle. } \\
\text { 5. Closure of vaginal opening by } 3-0 \text { polygalactin as interrupted intracorporeal suturing } \\
\text { 6. The bladder closed as running suture of } 3-0 \text { polygalactin } \\
\text { 7. Assessment of watertight closure of bladder by gentle distension with } 200-300 \mathrm{ml} \text { of normal saline filled under } \\
\text { gravity } \\
\text { 8. Omental flap interposition and tucked at the vaginal suture line }\end{array}$ \\
\hline Step IV & $\begin{array}{l}\text { 1. Soft silastic drain placement under vision in pelvis by side of bladder } \\
\text { 2. Termination of the pneumoperitoneum and port site closure } \\
\text { 3. Change of the vaginal packing with antiseptic soaked cotton gauze piece } \\
\text { 4. Patient shifting to specialized postoperative recovery room }\end{array}$ \\
\hline
\end{tabular}

Table 3. The advantages of laparoscopic VVF repair

Advantages

1 Respects the basic surgical principle of transabdominal VVF repair

2 Wide magnified, well illuminated and almost blood free surgical field

3 Wide exposure allows excision of fibrotic and unhealthy tissue

4 Clear identification of ureteric orifices avoids the risk of injury and also adds confidence to the surgeon

5 Tension free closure of fistulous opening including cystotomy

6 Suture material of any choice can be sued for intracorporeal suturing

7 Interposition flaps such as omentum, peritoneal folds, posterosuperior peritoneal covering of bladder and tinea epiploic of sigmoid colon can be used

8 Effective postoperative drainage and closed peritoneal drainage can be similarly employed like transabdominal repair

9 Associated pelvic pathology can be dealt simultaneously

10 Early ambulation and recovery

11 Less postoperative morbidity

12 Less postoperative pain reflected as less analog visual pain score

13 Less hospital stay in comparison to open VVF repair

14 Comparatively shorter convalescence

of bridging the limitations of laparoscopic surgery while maintaining the benefits of minimally invasive surgery. The robotic view is superior because of 3-dimensional picture with a 10 magnification, with wristed instru- mentation, ergonomic manipulation. In robot assisted VVF repair, the initial dissection and excision of fistulous tract are done laparoscopically; the robot is used for suturing of vaginal lumen and closure of cystotomy. The 


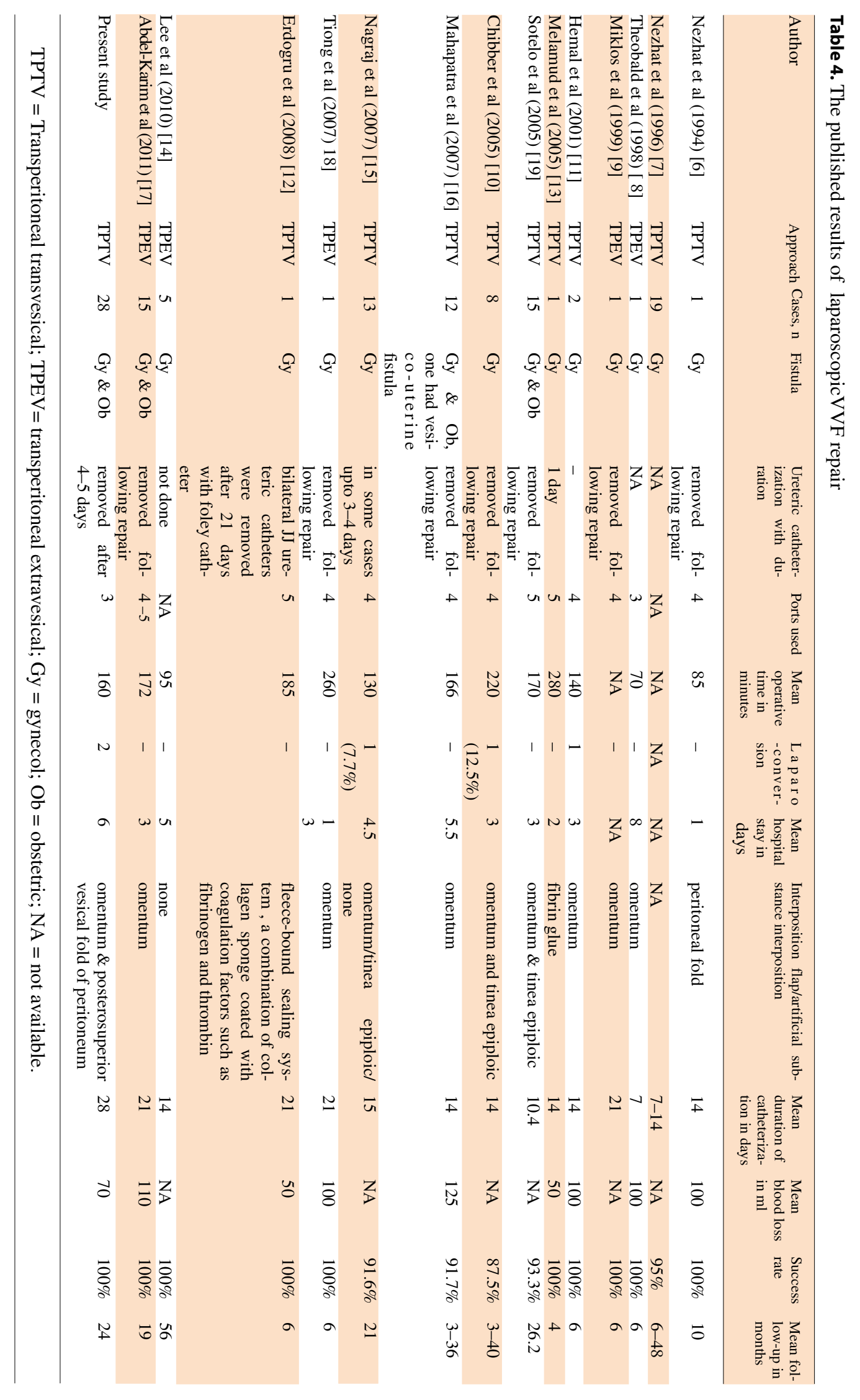


interposition could be the fibrin glue inserted between the suture lines [13]. In pure robotic VVF repair the entire procedure is done under robotic control with omentum as interposition flap $[20,21]$. The major limitation of robotic VVF repair is the high cost in comparison with lower cost of laparoscopic VVF repair which maintains high success rate similar to robotic repair [20].

The interposition flap particularly omentum is well vascularized tissue which provides vascularity, prevents the apposition of the suture lines and its rich lymphatics enhances the drainage of inflammatory fluids from surgical field. Proponents of omental interposition reports the increase success rate of fistula closure $[10-12,14,16$, 19] while some of the studies have not used the omentum $[15,17,18]$. In transvaginal or transabdominal VVF repair, interposition flaps are traditionally being used but recently some of the studies showed that it is of no use. Browning in a interesting study claimed that Martius flap raised in transvaginal repair is of no use in enhancing the success of repair, but the main drawbacks of this study are the retrospective study in which author suggested that flap should only be omitted by experienced fistula surgeons [22]. Rangnekar et al. [23] supports the use of Martius flap to increase the success of repair. In laparoscopic VVF repair the experience of intracorporeal suturing varies from surgeon to surgeon and the outcome of fistula surgery also depends upon on nature of fistula e.g. obstetric versus gynecologic fistula and hence interposition flap must be used. In present study we employed the omentum in 26 cases including two open conversions and posterosuperior vesical fold of peritoneum in 2 cases respectively.

The ideal surgical approach to a case of VVF depends upon the cause, location, size, number, and time of onset and the experience of surgeon. The inclusion criteria for laparoscopic repair in published papers are the single, supratrigonal, $<2.5 \mathrm{~cm}$, not amenable to transvaginal repair. The majorities of studies included gynecologic fistula $[11,15-19]$ and a few of them have both obstetric and gynecologic types $[10,12,14,16]$. In present study the gynecologic fistula was present in 10 and obstetric fistula in 18, of whom one patient had previous history of obstructed labour with ruptured uterus and bladder for which she was managed by exploratory laparotomy, repair of uterus and bladder. She developed supratrigonal fistula following this surgical intervention. In present study 2 patients had 2 fistulae lying side by side, which were repaired successfully in the same operation.

The ports placement and the internal dissections are the main cause of postoperative pain following laparo-

Laparoscopic Repair of Vesicovaginal

Fistulae scopic repair. Some of the studies have used 4 ports [11, $12,15,16,18,19]$ while others have used 5 to 6 ports $[10,14,15,17]$. In present study all cases were done using 3 ports only (table 4). The duration of Foley catheterization in reported studies varies between 10 days to 28 days [14]. In our patients we kept the bilateral ureteric catheters in all cases for 4 to 5 days with urethral catheters. The ureteric catheter additionally drains the pelvicaliceal system apart from the bladder drainage by Foley catheter. The Foley catheter was removed after 4 weeks all our patients.

The operative time in literature ranges from 70 to 280 minutes [10-19]. In present study our mean operative time is 160 minutes (range 140-200 minute). The operative time might depend on patient characteristics such as the presence of previous abdominal surgery and history of failed fistula repair. It also depends on surgical skill of laparoscopic surgeon. The mean reported follow-up in different series varies between 6 months and 40 months (table 4). In present study the median follow-up is 24 months (range 4-54 months). There was no recurrence in any of the case. The reported overall success rate in literature is 86 to $100 \%$ [10-19]. In our series the success rate is $100 \%$ which was due to good preoperative preparations such as correction of anemia $\&$ hypoprotenemia, meticulous dissection and interposition flaps in all cases and use of suitable suture material (3-0 polygalactin). The good bladder drainage was ensured by putting $18 \mathrm{~F}$ Foley catheters and ureteric catheters in all cases and also for 48 hours we put the patient in reverse Trendelenburg $\left(15^{\circ}\right)$ position to ensure the minimal contact of urine to the bladder suture line. All repairs were performed by single experienced urologist trained in laparoscopy and intracorporeal suturing.

\section{Conclusions}

Laparoscopic transperitoneal transvesical VVF repair is safe, effective minimally invasive procedure with excellent outcome. In select subgroup of supratrigonal fistulae it should be the procedure of choice. 


\section{References}

1 Goodwin WE, Scardino PT: Vesicovaginal and ureterovaginal fistulas: a summary of 25 years of experience. J Urol 1980;123:370 374.

$>2$ Kelly J, Kwast BE: Epidemiologic study of vesicovaginal fistulas in Ethiopia. Int Urogynecol J 1993;4:278-281.

3 Carr LK, Webster GD: Abdominal repair of vesicovaginal fistula. Urology 1996;48:10 11.

4 O'Conor VJ Jr, Sokol JK, Bulkley GJ, Nanninga JB: Suprapubic closure of vesicovaginal fistula. J Urol 1973;109:51-54.

$\checkmark 5$ Goyal NK, Dwivedi US, Vyas N, Rao MP, Trivedi S, Singh PB: A decade's experience with vesicovaginal fistula in India. Int Urogynecol J Pelvic Floor Dysfunct 2007; 18:39_ 42.

-6 Nezhat CH, Nezhat F, Nezhat C, Rottenberg $\mathrm{H}$ : Laparoscopic repair of a vesicovaginal fistula: a case report. Obstet Gynecol 1994;83: 899-901.

$>7$ Nezhat CH, Seidman DS, Nezhat F, Nezhat F, Rottenberg H, Nezhat C: Laparoscopic management of intentional and unintentional cystotomy. J Urol 1996;156:1400-1402.

8 von Theobald P, Hamel P, Febbraro W: Laparoscopic repair of a vesicovaginal fistula using an omental J flap. Br J Obstet Gynaecol 1998;105:1216-1218.
9 Miklos JR, Sobolewski C, Lucente V: Laparoscopic management of recurrent vesicovaginal fistula. Int Urogynecol J Pelvic Floor Dysfunct 1999;10:116-117.

10 Chibber PJ, Shah HN, Jain P: Laparoscopic O'Conor's repair for vesico-vaginal and vesico-uterine fistulae. BJU Int 2005;96:183186.

11 Hemal AK, Kumar R, Nabi G: Post-cesarean cervicovaginal fistula: technique of laparoscopic repair. J Urol 2001;165:1167-1168.

12 Erdogru T, Sanli A, Celik O, Baykara M: Laparoscopic transvesical repair of recurrent vesicovaginal fistula using with fleece-bound sealing system. Arch Gynecol Obstet 2008; 277:461-464.

13 Melamud O, Eichel L, Turbow B, Shanberg A: Laparoscopic vesicovaginal fistula repair with robotic reconstruction. Urology 2005; 65:163-166.

$>14$ Lee JH, Choi JS, Lee KW, Han JS, Choi PC, Hoh JK: Immediate laparoscopic nontransvesical repair without omental interposition for vesicovaginal fistula developing after total abdominal hysterectomy. JSLS 2010;14: 187-191.

15 Nagraj HK, Kishore TA, Nagalaksmi S: Early laparoscopic repair for supratrigonal vesicovaginal fistula. Int Urogynecol J Pelvic Floor Dysfunct 2007;18:759-762.
16 Das Mahapatra P, Bhattacharyya P: Laparoscopic intraperitoneal repair of high-up urinary bladder fistula: a review of 12 cases. Int Urogynecol J Pelvic Floor Dysfunct 2007;18: 635-639.

17 Abdel-Karim AM, Mousa A, Hasouna M, Elsalmy S: Laparoscopic transperitoneal extravesical repair of vesicovaginal fistula. Int Urogynecol J 2011;22:693-697.

18 Tiong HY, Shim T, Lee YM, Tan JK: Laparoscopic repair of vesicovaginal fistula. Int Urol Nephrol 2007;39:1085-1090.

19 Sotelo R, Mariano MB, Segui AG, Dubois R, Spaliviero M, Keklikian W, Novoa J, Yaime H, Finelli A: Laparoscopic repair of vesicovaginal fistula. J Urol 2005;173:1615-1618.

20 Hemal AK, Kolla SB, Wadhwa P: Robotic reconstruction for recurrent supratrigonal vesicovaginal fistulas. J Urol 2008;180:981-985.

21 Sundaram BM, Kalidasan G, Hemal AK Robotic repair of vesicovaginal fistula: case series of five patients. Urology 2006;67:970 973.

22 Browning A: Lack of value of the Martius fibrofatty graft in obstetric fistula repair. Int $\mathbf{J}$ Gynaecol Obstet 2006;93:33-37.

23 Rangnekar NP, Imdad Ali N, Kaul SA, Pathak HR: Role of the Martius procedure in the management of urinary-vaginal fistulas. J Am Coll Surg 2000;191:259-263. 